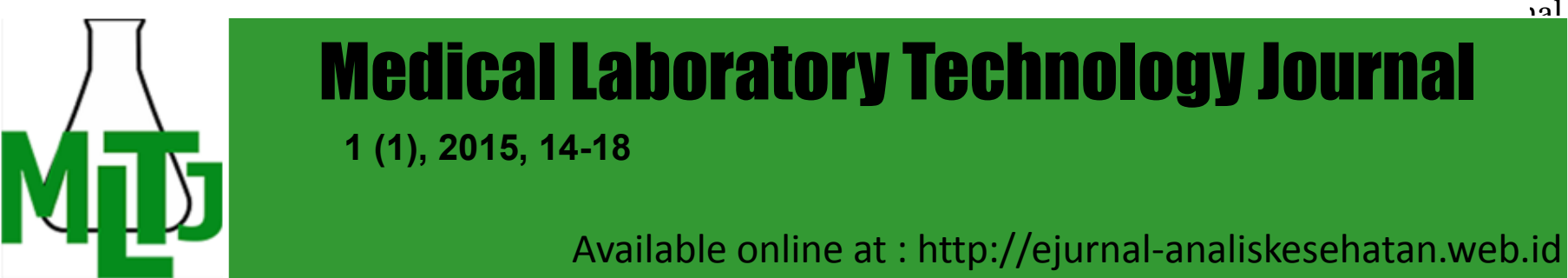

\title{
KANDUNGAN IODIUM PADA GARAM DAPUR DI PASAR BATUAH MARTAPURA MARET 2014
}

\author{
Haitami \\ Jurusan Analis Kesehatan Poltekkes Kemenkes Banjarmasin \\ JIn. Mistar Cokrokusumo N0. 4A Simpang Empat Banjarbaru \\ e-mail: haitami4@yahoo.co.id
}

\begin{abstract}
Research on the content of iodine in salt Kitchen in the Market Martapura March 2014 aims to determine the iodine content in the salt that is sold in the market Batuah Martapura and look for compliance with quality standards ISO 01-3556.2-1994 / Rev 2000. The method used in this study is a descriptive survey. The sample used in this study is a salt-branded and not branded, with a total sampling technique sampling. The research found $67 \%$ salt containing $\mathrm{KIO} 3$, and $33 \%$ of salt that does not contain $\mathrm{KIO} 3, \mathrm{KIO} 3$ in salt levels ranged from $8.68 \mathrm{ppm}$ $79.94 \mathrm{ppm}, 53 \%$ salt that does not qualify SNI and only $47 \%$ were eligible, $100 \%$ salt not branded ineligible SNI and 42\% SALT branded ineligible SNI. The public to be cautious in buying salt consumption for everyday purposes, and to the relevant agencies to conduct outreach and firm action against violations that exist in society against the marketing of salt that does not comply with permitted.
\end{abstract}

Keywords: salt branded and not branded, Kadar KIO3

Abstrak: Penelitian tentang Kandungan Iodium pada Garam Dapur di Pasar Martapura Maret 2014 bertujuan untuk menentukan kandungan iodium yang ada pada garam dapur yang dijual di Pasar Batuah Martapura serta melihat kesesuaiannya dengan baku mutu SNI 01-3556.21994/Rev 2000. Metode yang digunakan dalam penelitian ini adalah Survey Deskriptif. Sampel yang digunakan dalam penelitian adalah garam bermerk dan tidak bermerk, dengan teknik pengambilan sampel secara total sampling. Hasil penelitian ditemukan $67 \%$ garam yang mengandung $\mathrm{KIO}_{3}$, dan $33 \%$ garam yang tidak mengandung $\mathrm{KIO}_{3}$, Kadar $\mathrm{KIO}_{3}$ dalam garam berkisar antara 8.68 ppm - 79.94 ppm, 53\% garam yang tidak memenuhi syarat SNI dan hanya $47 \%$ yang memenuhi syarat, $100 \%$ garam tidak bermerk tidak memenuhi syarat SNI dan $42 \%$ GARAM bermerk tidak memenuhi syarat SNI. Masyarakat agar berhati-hati dalam membeli garam konsumsi untuk keperluan sehari-hari, dan kepada instansi terkait agar melakukan penyuluhan dan tindakan yang tegas terhadap pelanggaran yang ada di masyarakat terhadap pemasaran garam yang tidak sesuai dengan yang diizinkan.

Kata kunci: Garam bermerk dan tidak bermerk, Kadar $\mathrm{KIO}_{3}$

\section{PENDAHULUAN}

Kekurangan lodium masih menjadi masalah besar di beberapa negara di dunia, khususnya negara-negara berkembang. Dilaporkan sekitar $38 \%$ dari jumlah penduduk dunia terkena risiko gangguan akibat kekurangan iodium (GAKI). Kekurangan iodium dapat menyebabkan gondok, terjadinya kretinisme, menurunnya kecerdasan, gangguan pada otak, bisu-tuli, serta pada ibu hamil dapat menyebabkan keguguran dan kematian pada bayi (Burhanudin,2001).

Untuk mengatasi kekurangan asupan iodium dalam makanan, pemerintah membuat program penggunaan garam beriodium dengan menambahkan (suplementasi) kalium iodat ke dalam garam dapur. Kekurangan iodium dapat disebabkan oleh asupan makanan yang kurang mengandung iodium atau mengkonsumsi garam beriodium yang tidak sesuai standar (BPOM RI, 2006). 
Meskipun iodium merupakan mineral yang diperlukan oleh tubuh dalam jumlah relatif kecil, tetapi mempunyai peranan yang sangat penting untuk pembentukan hormon tiroksin. Hormon tiroksin ini sangat berperan dalam metabolisme di dalam tubuh (Gunung, 2004). Hormon tiroksin ini sangat berperan dalam metabolisme di dalam tubuh (Gunung, 2004).

Hampir seluruh makanan yang diolah menggunakan garam sebagai penyedap rasa, serta banyak digunakan untuk bahan tambahan dalam industri pangan, selain itu, karena harga garam dapur relatif murah dan terjangkau oleh semua lapisan masyarakat maka pemerintah memilih garam dapur menjadi garam konsumsi sebagai media penyampaian iodium ke dalam tubuh (Purnawati, 2006)

Permasalahan yang timbul dimasyarakat sampai saat ini ternayata masih banyak beredar garam dapur yangtidak memenuhi standar yang diizinkan untuk garam dapur. Hal ini terbukti dari hasil penelitian Kapantow (2013) dari 10 sampel garam dapur yang diperiksa ada $50 \%$ sampel yang tidak memenuhi syarat dan 5 sampel memenuhi persyaratan SNI. Hasil penelitan Chairunnisa (2010) tentang penggunaan garam beriodium di Kecamatan Amuntai Tengah juga didapatkan $26.5 \%$ garam yang tidak memenuhi persyaratan SNI Nomor 01-3556.21994/Rev 2000 garam konsumsi beriodium antara 30-80 ppm. Hasil penelitian pada garam dapur yang tidak memenuhi persyaratan memiliki kadar dari 0,3 ppm-28 ppm. Hal ini menunjukkan bahwa mutu dalam garam ini masih sangat jauh dari kualitas yang seharusnya, hal ini dapat terjadi karena produksi pembuatan garam di Indonesia yang masih tradisional, sistem pengawasan yang belum efektif serta belum diberlakukannya sanksi secara tegas, karena $\pm 90 \%$ produsennya adalah termasuk pengusaha kecil (Sudarmadji, 2010). Menurut DepKes RI Perusahaan yang belum menerapkan SNI pada umumnya adalah industri kecil yang berada di sentra produksi yang perlu dibina sistem manajemen mutu, pelatihan teknik produksi dan bantuan peralatan mesin iodisasi garam dimana peralatan iodisasi yang digunakan produsen masih sederhana, sehingga kadar iodium dalam garam tidak homogen (Kapantow, 2013). Oleh karena itu peneliti tertarik melakukan penelitian tentang berapa kandungan iodium dalam garam dapur yang dinyatakan sebagai $\mathrm{KIO}_{3}$ dan membandingkannya dengan Baku Mutu SNI Nomor 01-3556.2-1994/Rev 2000.

\section{BAHAN DAN METODE \\ Rancangan Penelitian}

Jenis penelitian ini adalah penelitian Survey Deskriptifyaitu suatu penelitian yang bertujuan untuk menggambarkan kandungan lodium yang terdapat dalam garam dapur yang beredar di Pasar Martapura (Syarif, 2012).

\section{Sumber Data}

Data yang digunakan dalam penelitian ini adalah Data Primer yang berasal dari hasil pemeriksaan Kadar lodium yang dinyatakan sebagai $\mathrm{KIO}_{3}$ dalam garam dapur dengan menggunakan metode titrasi lodometri.

Populasi dalam penelitian ini adalah garam dapur bermerk dan tidak bermerk yang dijual di Pasar Batuah Martapura yang berjumlah 15 jenis. Sampel dalam penelitian ini dilakukan secara total sampling dan diambil secara simple random sampling dimana masing-masing jenis garam dapur diambil 1 bungkus untuk dijadikan sampel penelitian.

\section{Teknik Pengumpulan Data}

Garam dapur yang telah dipilih sebagai sampel penelitian kemudian diperiksa kadar lodiumnya (uji kuantitatif) dengan cara sebagai berikut: ditimbang dengan teliti $25,0 \mathrm{~g}$ garam dapur, dilarutkan dengan $125 \mathrm{~mL}$ aquadest, kemudian $+2 \mathrm{~mL} \mathrm{H}_{3} \mathrm{PO}_{4} 85 \%+1 \mathrm{~g}$ $\mathrm{KI}$ dan $1 \mathrm{~mL}$ amylum $1 \%$, dititrasi dengan larutan $\mathrm{Na}_{2} \mathrm{~S}_{2} \mathrm{O}_{3} 0,0050 \mathrm{~N}$ sampai warna biru tepat hilang. Setelah itu dihitung kadar iodium yang dinayatakan sebagai $\% \mathrm{KIO}_{3}$. Sedangkan uji kualitatif dilakukan dengan melihat perubahan warna dalam larutan, dimana hasil positif bila terbentuk warna biru, dan hasil negatif jika larutan tetap bening setelah penambahan reagensia (Anonim, 2006).

\section{Analisis Data}

Data yang diperoleh dikumpulkan dan ditabulasi, kemudian di analisa secara deskriptif dengan menggunakan tabel, diuraikan dalam bentuk persentase dan kadar iodat dalam garam dapur dibandingkan dengan baku mutu menurut SNI 01-3556.21994/Rev 2000. 
HASIL DAN PEMBAHASAN

Pada penelitian ini, sebelum dilakukan uji kuantitatif (pemeriksaan kadar), sebelumnya diamati uji kualitatif terhadap iodat $\left(\mathrm{IO}_{3}{ }^{-}\right)$yang terdapat dalam sampel, walaupun dalam sampel garam dapur beriodium bermerk pada kemasannya mengandung kalium iodat. Adapun uji kualitatif untuk menentukan ada tidaknya iodat dalam sampel didasarkan atas prinsip reaksi redoks antara iodat dengan iodida $\left(\mathrm{I}^{-}\right)$ dalam suasana asam akan menghasilkan iodad $\left(\mathrm{I}_{2}\right)$ yang berwarna kuning kecoklatan, dan jika ditambah amylum akan membentuk kompleks iod_amylum yang berwarna biru kehitaman. Reakasi yang terjadi adalah sebagai berikut (Ham,2009):

$$
\begin{gathered}
\mathrm{IO}_{3}^{-}+5 \mathrm{I}^{-}+6 \mathrm{H}^{+}+\text {à } 3 \mathrm{I}_{2}+3 \mathrm{H}_{2} \mathrm{O} \\
\mathrm{I}_{2}+\text { Amylum à lod-Amylum }
\end{gathered}
$$

(Biru kehitahamn).

Berdasarkan uji kualitatif yang dilakukan baik pada garam bermerk maupun pada garam tidak bermerk diperoleh hasil seperti yang ditunjukkan dalam Tabel 1.

Tabel 1. Hasil Uji Kualitatif iodat Garam Dapur Bermerk dan Tidak Bermerk.

\begin{tabular}{|l|c|l|l|}
\hline No & Merek & \multicolumn{1}{|c|}{ Hasil } & \multicolumn{1}{|c|}{ Ket } \\
\hline 1 & A & Bening & Negatif \\
\hline 2 & B & Bening & Negatif \\
\hline 3 & C & Biru & Positif \\
\hline 4 & D & Bening & Negatif \\
\hline 5 & E & Biru & Positif \\
\hline 6 & F & Biru & Positif \\
\hline 7 & G & Biru & Positif \\
\hline 8 & H & Biru & Positif \\
\hline 9 & I & Biru & Positif \\
\hline 10 & $\mathrm{~J}$ & Biru & Positif \\
\hline 11 & K & Biru & Positif \\
\hline 12 & L & Biru & Positif \\
\hline 13 & $\mathrm{M}^{*}$ & Biru & Positif \\
\hline 14 & $\mathrm{~N}^{*}$ & Bening & Negatif \\
\hline 15 & $\mathrm{O}^{*}$ & Bening & Negatif \\
\hline
\end{tabular}

Catatan: *) Sampel garam tanpa merk.

Tabel 1. menunjukkan bahwa dari 15 sampel yang diperiksa 5 sampel tidakmen- gandung iodat di dalamnya, dan 10 sampel yang positif mengandung iodat. Sampel yang positif mengandung iodat, dilanjutkan penentuan kadarnya menggunakan metode titrasi iodometri (Tabel 2)

\begin{tabular}{|r|c|c|l|}
\hline No & Merek & Hasil & \multicolumn{1}{|c|}{ Ket } \\
ra- \\
bel \\
\hline 1 & A & 0 & Abnormal \\
\hline 2 & $\mathrm{~B}$ & 0 & Abnormal \\
\hline 3 & $\mathrm{C}$ & 60,91 & Normal \\
\hline 4 & $\mathrm{D}$ & 0 & Abnormal \\
\hline 5 & $\mathrm{E}$ & 23,29 & Normal \\
\hline 6 & $\mathrm{~F}$ & 79,94 & Normal \\
\hline 7 & $\mathrm{G}$ & 76,79 & Normal \\
\hline 8 & $\mathrm{H}$ & 62,06 & Normal \\
\hline 9 & $\mathrm{I}$ & 67,29 & Normal \\
\hline 10 & $\mathrm{~J}$ & 73,99 & Normal \\
\hline 11 & $\mathrm{~K}$ & 8,68 & Abnormal \\
\hline 12 & $\mathrm{~L}$ & 60,25 & Normal \\
\hline 13 & $\mathrm{M}^{*}$ & 22,17 & Normal \\
\hline 14 & $\mathrm{~N}^{*}$ & 0 & Abnormal \\
\hline 15 & $\mathrm{O}^{*}$ & 0 & Abnormal \\
\hline
\end{tabular}

Hasil Pengukuran Kadar $\mathrm{KIO}_{3}$ dalam Garam

Catatan:*) Sumber data primer hasil pengukuran di laboratorium Kimia Terapan Analis Kesehatan.

Berdasarkan hasil uji kualitatif yang ditunjukkan pada Tabel 1. diketahui bahwa dari 15 sampel garam yang diperiksa, terdapat 5 sampel garam $(33 \%)$ yang tidak mengandung iodat, dan hanya 10 sampel garam (67\%) yang mengandung iodat. Prosentase tingkat kepositifan iodat dalam garam ditunjukkan oleh Gambar 1.

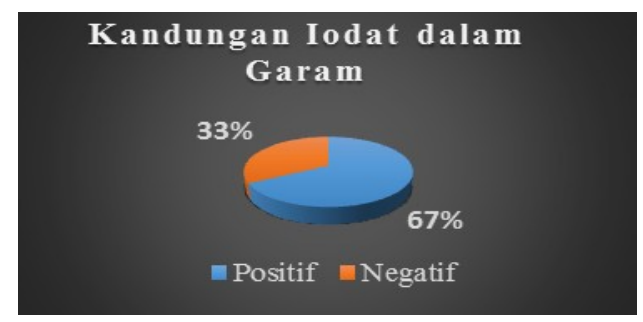

Gambar 1. Prosentase Tingkat Positif dan Negatif Kandungan lodat 
Lima sampel garam yang tidak mengandung iodat di dalamnya ternyata tidak hanya didapatkan pada garam yang tidak bermerk saja, dimana berdasarkan atas hasil penelitian yang ditunjukkan dalam Tabel 4.1. diketahui bahwa ada 3 sampel dari garam bermerk yang mencantumkan kadar iodat sebagai $\mathrm{KIO}_{3}$ di dalam kemasannya, ternyata setelah diuji secara kualitatif hasilnya negatif. Dan dari 3 sampel dari garam bermerk yang mencantumkan kadar iodat sebagai $\mathrm{KIO}_{3}$ di dalam kemasannya, ternyata setelah diuji secara kualitatif hasilnya negatif. Dan dari 3 sampel garam tidak bermerk ternyata dua sampel yang tidak mengandung iodat di dalamnya.

Berdasarkan persyaratan SNI Nomor 013556-2-1994/Rev 2000 garam konsumsi berio- dium harus mengandung iodium yang dihitung sebagai kalium iodat berkisar antara $30-80$ ppm. Hasil uji kuantitatif yang dilakukan pada penelitian ini ternyata dari 15 sampel garam yang diperiksa sebagian besar ditemukan garam yang tidak memenuhi persyaratan SNI untuk kadar iodat di dalamnya. Dimana 8 sampel garam $(53 \%)$ yang tidak memenuhi syarat untuk dikonsumsi, dan hanya 7 sampel garam $(47 \%)$ yang memenuhi syarat. Dan dari semua jenis garam tidak bermerk ternyata semuanya $(100 \%)$ tidak ada yang memenuhi syarat SNI. Meskipun ada satu garam bermerk yang mengandung iodat, tapi kadarnya masih di bawah baku mutu yang diizinkan. Jumlah garam yang memenuhi syarat baku mutu (SNI 01-3556.21994/Rev 2000) dapat dilihat pada Gambar 2.

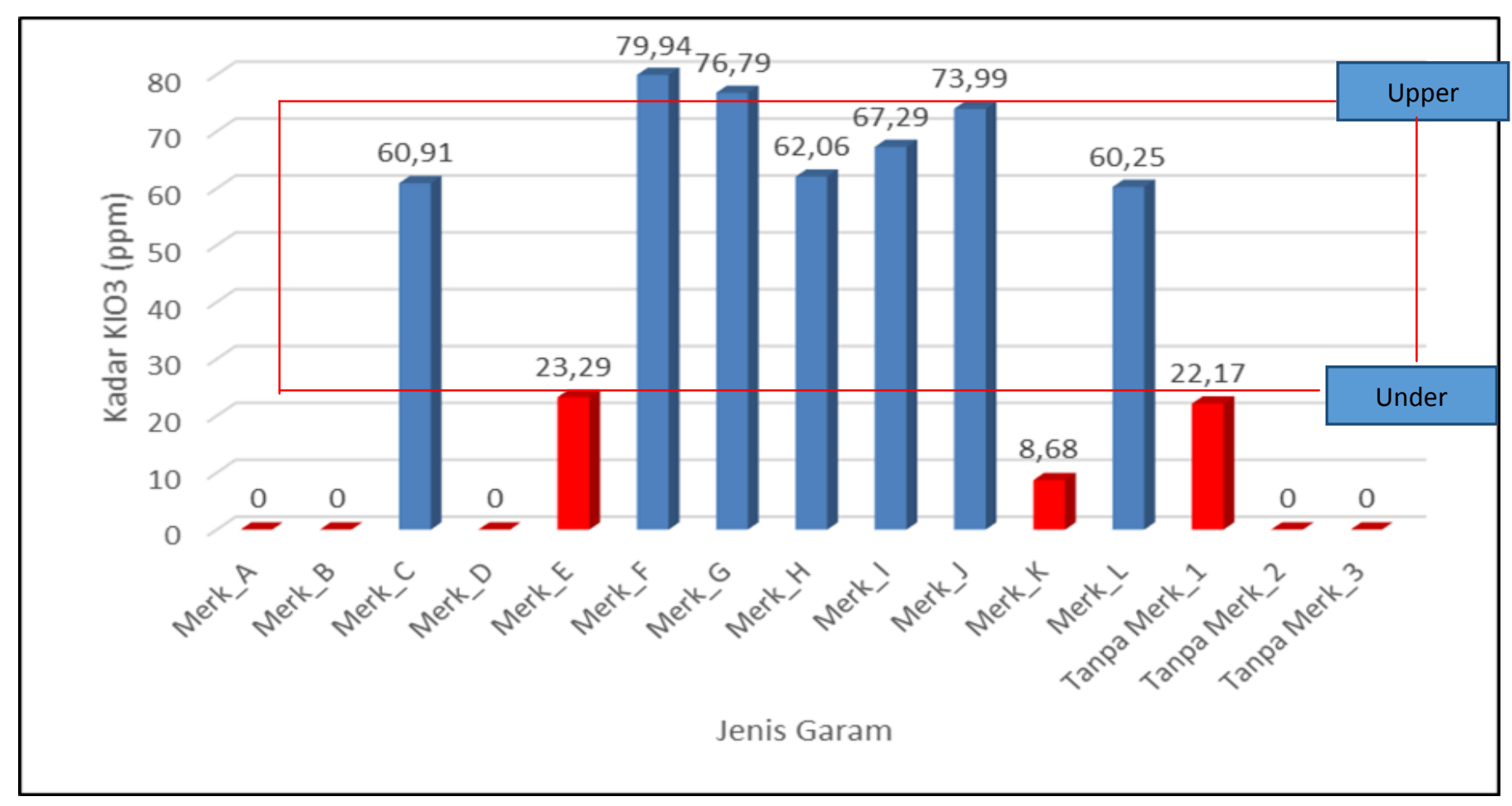

Gambar 2. Hasil Kadar lodat pada Garam

Gambar 2 menunjukkan sampel garam dalam penelitian ini yang tidak memenuhi persyaratan ternyata hanya mengandung $\mathrm{KIO}_{3}$ dari 0 ppm - 23,29 ppm. Semua kadar iodatnya berada di bawah baku mutu yang diizinkan. Yaitu pada Garam Bermerk_A (0 ppm), Garam Bermerk_B (0 ppm), Garam Bermerk_D (0 ppm), Garam Bermerk_E (23,29 ppm), Garam Bermerk_K (8,68 ppm), Garam Tanpamerk_1 (22,17 ppm), Garam Tanpamerk_2 (0 ppm), dan Garam Tanpamerk_3 (0 ppm). Artinya mutu dalam garam ini masih sangat jauh dari kualitas yang seharusnya, hal ini dapat terjadi karena produksi pembuatan garam di Indonesia yang massih tradisional, sistem pengawasan yang belum efektif serta belum diberlakukannya sanksi secara tegas, karena $\pm 90 \%$ produsennya adalah termasuk pengusaha kecil (Kapantow, 2013). Menurut Depkes RI Perushaan yang belum menerapkan SNI pada umumnya adalah industri kecil yang berada di sentra produksi yang perlu dibina sistem manajemen mutunya, pelatihan teknik produksi dan bantuan peralatan mesin iodisasi yang digunakan produsen masih sederhana, sehingga kadar iodium dalam garam tidak homogen. 
Adapun 7 sampel garam lainnya yang diperiksa dalan penelitian ini mengandung kalium iodat dengan kadar sesuai dengan persyaratan SNI, dengan kadar berkisar antara 60,25 ppm - 79,94 ppm. Semuanya ada pada garam bermerk, Yaitu pada Garam Merk_C (60,91 ppm), Garam Merk_F $(79,94$ ppm), Garam Merk_G (76,79 ppm), Garam Merk_H (62,06 ppm), Garam Merk_I $(67,29$ ppm), Garam Merk_J (73,99 ppm), dan Garam Merk_L (60,25 ppm).

Berdasarkan penelitian ini dapat digambarkan bahwa dari beberapa sampel garam yang beredar di Pasar Batuah Martapura, mutu dan kualitas garam dapur sebagai garam konsumsi masih harus lebih ditingkatkan dan peredaran garam dapur dipasaran harus lebih diawasi untuk mencapai kecukupan gizi iodium bagi masyarakat (Kapantow, 2013). Apabila konsumsi garam beriodium dalam makanan rendah, dapat menyebabkan terjadinya defisiensi iodium bagi masyarakat. Akibat dari defisiensi iodium saat ini diketahui tidak hanya pembesaran kelenjar tiroid, tetapi jauh lebih luas yaitu keguuran, lahir mati, cact bawaan, keratin, dan hipotiroid (DGKM, 2007)

Untuk menghindari kerugian bagi konsumen akibat salah memilih garam dapur untuk dikonsumsi, sebaiknya masyarakat memilih garam dapur yang dijual bebas di pasaran memilih kemasan yang sesuai dengan Peraturan Menteri Perindustrian RI. No. 42/M-Ind/PER/II/2005 mengenani persyaratan pengemasan dan pelabelan garam beriodium yaitu garam yang akan dipasarkan wajib dikemas dalam wadah yang ditutup rapat sehingga aman selama pengangkutan dan penyimpanan, untuk menjamin ketepatan berat bersih garam, maka pengisian dan penimbangan oleh produsen harus dilakukan secara mekanis dan manua. Pada kemasan garam konsumsi harus ditulis dengan jelas keterangan berupa tulisan "Garam Beriodium", kandungan kalium iodat $\left(\mathrm{KIO}_{3}\right)$ minimal $30 \mathrm{ppm}$, berat bersih, tanda/logo SNI, nomor pendaftaran dari BPOM, komposis isi garam konsumsi, merk dagang, dan alamat perusahaan.

\section{KESIMPULANI}

Kesimpulan dari penelitian terhadap kadar $\mathrm{KIO}_{3}$ yang terdapat dalam garam bermerk dan tidak bermerk yang dijual di Pasar Batuah
Martapura adalah sebagai berikut 57\% sampel garam yang mengandung $\mathrm{KIO}_{3}$ dan $33 \%$ sampel garam yang tidak mengandung $\mathrm{KIO}_{3}$ di dalamnya. Kadar $\mathrm{KIO}_{3}$ dalam sampel garam berkisar antara 8.68 ppm - 79.94 ppm. $47 \%$ sampel garam yang memenuhi standar dan $53 \%$ yang tidak memenuhi syarat SNI 013556.2-1994/Rev 2000.

\section{DAFTAR PUSTAKA}

Anonim, (2006). Sumber-Sumber lodium.

Burhanuddin, (2001). Proceeding Forum Pasar Garam Indonesia, Badan Riset Kelautan dan Perikanan, Jakarta,

BPOM RI (2006).Vol. 7.No.3

Chairunnisa, (2010). Pengaruh Penggunaan Garam Beryodium Terhadap Status Gizi Balita Pendek di Kecamatan Amuntai Tengah Kabupaten Hulu Sungai Utara Tahun 2010 (skripsi), Sekolah Tinggi IImu Kesehatan Husada Borneo, Banjarbaru,

Gunung, I, K. (2004). Perhitungan Kadar lodium dalam Yodisasi Garam untuk Penanggulangan GAKI di Daerah Endemik. Majalah Kedokteran Udayana. Udayana

Kapantow AN, Fatimawali, Yudistira A, (2013). Identifikasi dan Penetapan Kalium lodat Dalam Garam Dapur yang Beredar di Pasar Kota Bitung dengan Metode Spektrofotometri UV-Vis, FMIPA UNSRAT, Manado

Purnawati, W. (2006). Pengaruh Teknik lodisasi dan Lama PenyimpananTerhadap Kadar Kaliumiodat (skripsi,) Fakultas MIPA UNS

Ham, Mulyono. (2009). Kamus Kimia. Jakarta: Bumi Aksara.

Sudarmadji, (2010). Ananlisa Bahan Makanan, Gramedia, Jakarta

Syarif Hamdani, Siti Uswatun Hasanah, Windari Safitri Romauli Situmorang, (2012). Panduan Praktikum Kimia Analisis, Sekolah Tinggi Farmasi Indonesia, Bandung 